\title{
Simulating Effects of Transportation Disruption on Supply Chain Based on Vendor Managed Inventory Approach
}

\author{
Afsaneh Noori Houshyar, Mohammad Reza Tavakoli Baghdadabad, Azadeh Noori Hoshyar, and Riza \\ Bin Sulaiman
}

\begin{abstract}
As competitions between firms become fiercer, they are constantly finding new ways to win the competition. They employed various initiatives such as outsourced manufacturing and increased product variety for increasing profit and customer satisfaction. Another strategy employed is supply chain management. However, managing supply chain presents certain challenges. There are a lot of risks like demand changes, transportation disruptions and natural disasters which can threat the stability of chain members and increases vulnerability of the whole supply chain. Examples of this includes; terrorist attacks on the world trade center on September 11, 2001, the SARS epidemic in south-East Asia and the recent H1N1 epidemic which led to costly disruptions in supply chain. A review of literature reveals that identifying risks and managing supply chain disruptions are important issues in supply chain management. Another important issue highlighted by literature is impact of information sharing on supply chain performance. Vendor managed inventory is new approach to supply chain which provide good information sharing among the chain's members. According to increscent of uncertainty which threats stability of supply chain and importance role of information sharing in today's supply chain, this research provides an attempts to investigate impacts of transportation disruption on proposed Vendor Managed Inventory. Simulation modeling is utilized as a useful tool for evaluating system efficiency and inventory level.
\end{abstract}

Index Terms - Supply chain management, vendor managed inventory, disruption, information sharing, disruption, simulation.

\section{INTRODUCTION}

Supply chain is defined as a chain which raw materials are procured, items are produced at one or more factories and transferred to distributor centre, then shipped to retailers, and finally reach to customer's hands. Demand at upstream part of chain depends on the orders which are created at downstream part and because of uncertainties which have been seen in the market, inventory managing and information sharing between the members for eliminating bullwhip effects become crucial issues. Vendor Managed Inventory (VMI) is recent approach to supply chain for information sharing. Based on this approach customer allows supplier to access to its inventory level and its sale data (point-of-sale for retailer). Supplier will use this information to plan and manage its customer's inventory. This means that supplier

Manuscript received November 25, 2012; revised March 7, 2013.

Afsaneh Noori Houshyar and Azadeh Noori Hoshyar are with University Putra Malaysia. (e-mail: a_nh86@yahoo.com).

Mohammad Reza Tavakkoli Baghdadabad and Riza Bin Sulaiman are with University Kebangsaan Malaysia. will take its customer's inventories into account in addition to its own inventories when making its inventory plan and replenishment. Indeed suppliers can calculate inventory levels, deliveries rates and minimize the costs by implementing VMI in a system. [1]. Therefore new concept leads to have closer relationship and collaboration in supply chain.

As Centre for Research on the Epidemiology of Disasters [2] observed the disasters have increased exponentially worldwide over the past decades. Therefore supply chain becomes more vulnerable to disruption during these years [3]. Unexpected disruption in supply chain can make negative effects on chain's performance, therefore, considering the probability of risk in chain becomes important. The terrorist attacks on 11 September 2001, the SARS epidemic in South-East Asia, the recent H1N1 epidemic that plagued the whole world and the most current Haiti earthquake are examples of risks which are faced by supply chains. By considering these happening during previous decade a lot of attentions goes to supply chain disruption and its management.

As many unanticipated events threat supply chain hence, simulation modeling is proposed as a useful tool for predicting impacts of disruption on chain [4].The main goal of simulation modeling is what-if analysis [5]. As simulation modeling is capable to capture uncertainty and complexity in supply chain, therefore, it becomes as a suitable tool to analyze supply chain and mitigate negative effects of disruption on chain. Indeed researchers via the simulation modeling are able to analyze impacts of disruption before it happens in reality.

This paper tries to investigate on impacts of transportation disruption in vendor managed inventory. The paper begins with a section on defining and proposing vendor managed inventory approach to an automotive supply chain. Disruptions in supply chain are illustrated in section III. In follows of section III, transportation disruption will be discussed. The impacts of transportation disruption in vendor managed inventory will be argued in section IV, simulation modeling and research results will be explained in section $\mathrm{V}$ and VI. Last section will be conclusion.

\section{VENDOR MANAGED INVENTORY APPROACH TO SUPPLY CHAIN}

Although Vendor Managed Inventory (VMI) is new concept, one of the successful business models which is used by Wal-Mart and many other retailers. VMI helps to have closer understanding and collaboration between supplier, 
manufacturer, distributor and retailer. VMI model try to share information (inventory level, demand data) between the chain's members via Electronic Data Interchange (EDI).

Under the VMI model of this study, information is shared between all members; upstream partner has inventory managing responsibility for its downstream partner. Upstream members create orders for their customer based on the information which is shared between the vendor and customer. In proposed VMI scenario, retailer's order come to the chain and will be checked by distributor. Simultaneously they share retailer's demand data with manufacturer via the EDI. The inventory level of distributor may be enough for responding to retailer's order or may not. If distributor does not have enough automotive inventories, retailer will decide whether wait or leave the system. If the available inventory be sufficient, distributor will load automotives and ship to retailer, and then inventory updating is done. Also they use EDI to inform manufacturer the current inventory level. Based on the information which has shared by EDI, manufacturer try to control distributor inventory, decide when and what quantity is needed to send automotive for distributor. After automotive shipment to retailer, manufacturer will control inventory level of distributor. If manufacturer perceives that inventory level of distributor fall down the Reorder Point (ROP), they decide to provide and send automotive to distributor. Manufacturer will check their own inventory, If sufficient automotive be available, they will load and send to distributor. Otherwise they decide to produce automotive based on the distributor's requirement. In this part manufacturer will transfer production planning to supplier via the EDI. Supplier will check raw material inventory level of manufacturer based on the production planning which is shared by manufacturer via the EDI, and then make decision that when and what quantity they must send to manufacturer. If supplier observations show that inventory level of raw material in manufacturer is sufficient for production; manufacturer will be aware of this and start their production. Otherwise supplier prepares the quantity of raw material which is needed by manufacturer, batch and ship to them. The inventory level of both raw material and finished product are updated after each deduction or increment.

Also after each deduction from raw material manufacturer use EDI to show the inventory level of raw material to the supplier. Supplier uses this information sharing for checking the inventory level.

\section{DisRUPTION IN SUPPLY CHAIN}

During the past five years a new subject in the field of supply chain management obtained a lot of attention to itself which was disruption in supply chain. Indeed after terrorist attack on the world trade center on September 2001, the SARS epidemic in south-east Asia in 2003, natural disaster of Hurricane Katrina in 2005, and the recent H1N1 epidemic which led to costly disruptions in supply chain, most of the researchers were interested in this topic [4]. The high regard that manager and firms are paying to disruption is triggered by the frequency and intensity of catastrophes, disasters and crises that have increased in the global scale [6], [7].

\section{TRANSPORTATION DiSRUPTION IN SUPPLy CHAIN}

The backbone of modern society and also the element which has the most important role in supply chain is transportation network. Therefore the reliability of this network is very crucial. Any threat to transportation network can be considered as a weakness for supply chain .Unreliable transportation network cause to extra cost for supply chain and also leads to system efficiency reduction [8]. Transportation disruption leads to making delay or stoppage in goods flow and also goods production. For instance the terrorist attack to Pentagon in 2001 lead to stoppage of many assembly lines of Ford just because of delayed at Canadian and Mexican border which had happened following of attack [9].

\section{Simulation Modeling}

Regarding to chain's complexity, simulation modeling is one of the few tools that can capture the dynamic nature of a system in realistic manner. One of the appropriate methods for assessing and predicting chain's performance in dynamic analysis of production and logistics processes is simulation.

Supply chain dynamics can be faced unanticipated disruptive events such as fire, flood, war, terrorist attack, transportation delays and so on. Most of the organizations are attempting to determine how to prepare themselves for such events before it happens. Supply chain simulation plays an important role in helping companies design redundant systems or mitigation plans to minimize the impacts of disruptive events [10]. For mitigating risk of supply chain disruptions and also decreasing the negative effects of that, an early warning is needed to sense the disruption earlier which can be done via simulation modeling.

\section{Simulation Results}

Risk and uncertainty continually threat the company's business but the greatest weakness of global supply chain is action gap towards the disruptions [11], therefore, this paper focus on impacts of transportation disruption on vendor managed inventory. Simulation modeling was applied for this mean; simulation modeling helps to clarify the sensitivity of proposed model to transportation disruption for an automotive supply chain.

The model was built in ARENA v.13 professional software. The simulated model was run in two statuses for five times over a time period of 12,000 hours by the warm up period of 500 hours. The first statues is Normal situation, in this situation all the chain's jobs are done based on exact scheduling and there is no delay on the supply chain but the second status is Transportation Disrupted situation which contains transportation disruption in whole chain. The simulation results were gathered for comparing the system efficiency and inventory level of members in these two statuses. The obtained results are as follows:

\section{A. Percentage of System Efficiency}

As shown in Fig. 3, when the transportation disruption 
occurred in VMI model the efficiency of system will decrees from $84 \%$ to $74 \%$.In the normal situation the number of orders which has been responded by the system is 53544 but in the transportation disrupted situation this responded order is reduced to 47141 where the total number of incoming orders is 63546 (Fig.1 and Fig. 2).Comparison of Fig. 1 and Fig. 2 depict that, number of lost orders or not responded orders has increased by transportation disruption. As results show transportation delays lead to decrement of customer satisfaction and system performance. The calculations are as follows:

System efficiency $=($ Number of Output $\div$ Number of Input $)$

System efficiency (Normal Situation): $(53544 \div 63546) \times$

$100=84 \%$

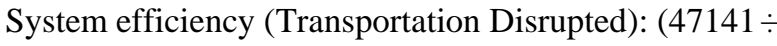

63546) $\times 100=74 \%$

Therefore, the reduction of efficiency can be obtained here according to following calculation;

Reduction of system efficiency in VMI model is: (84\% $74 \%) \div 84 \%=12 \%$

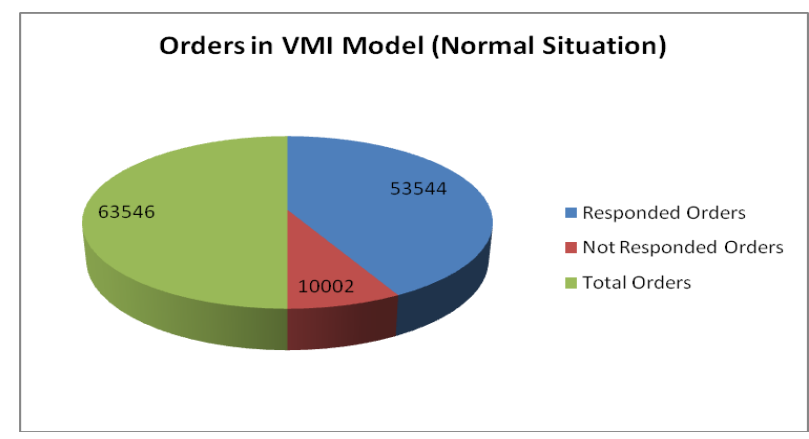

Fig. 1. Orders in VMI model (normal situation)

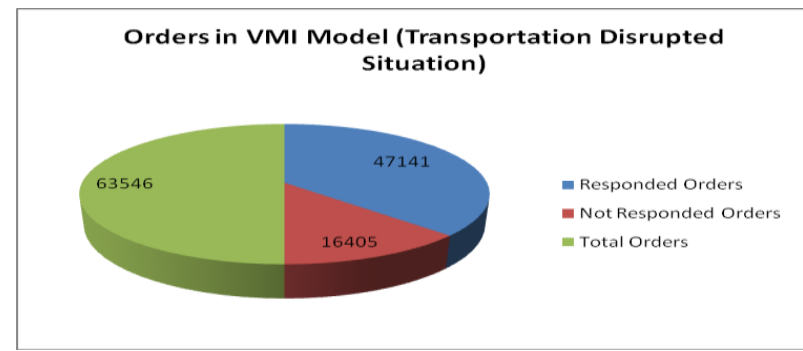

Fig. 2. Orders in VMI (transportation disrupted situation)

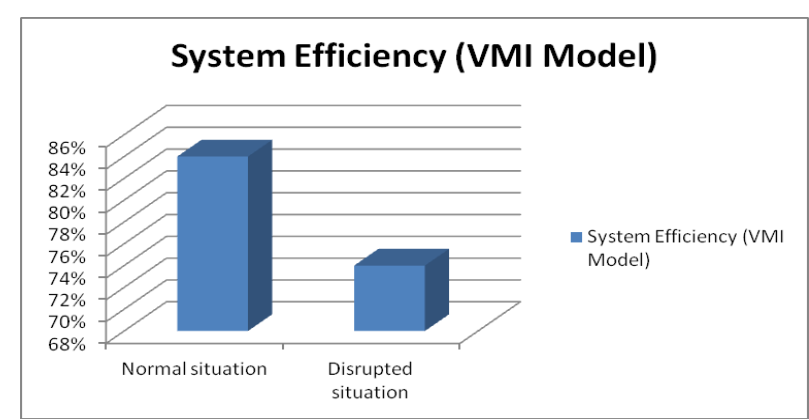

Fig. 3. Comparison of VMI in two situations

\section{B. Manufacturer Inventory (Material) and (Product) Level}

The manufacturer inventory (Material) and (Product) which have gained after 5 times simulation running in two status of Normal and Transportation Disrupted are as follows:.

\section{VMI model (Normal Situation):}

Average Manufacturer inventory (Material): 2093 units Average Manufacturer inventory (Product): 1636 units VMI model (Transportation Disrupted):

Average Manufacturer inventory (Material): 1993 units

Average Manufacturer inventory (Product): 1532 units

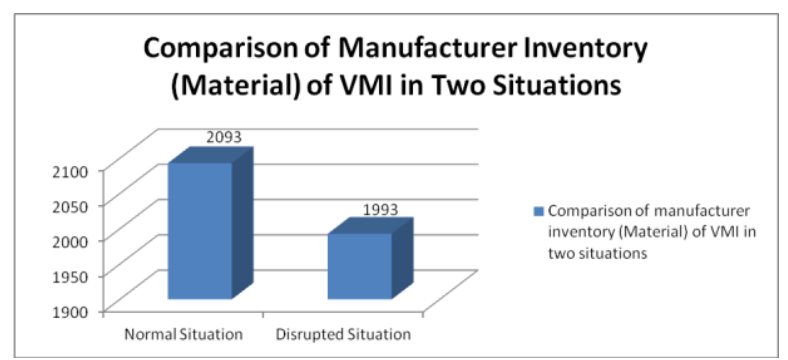

Fig 4. Comparison of Manufacturer Inventory (Material) of VMI in Two Situations

As Fig. 4 and Fig. 5 represent since transportation disruption happens in the system between supplier manufacturer and also manufacturer - distributor simultaneously, therefore, the average inventory level of manufacturer (Material) and Manufacturer (Product) will decreases after disruption. In the other words since there is a delay between manufacturer and supplier, therefore, there will be a shortage of material for the Manufacturer (Material) warehouse, In consequence of this shortage the production line also will face the problem in order to producing, hence, the warehouse of Manufacturer (product) also cannot be full-filled based on its planning. Indeed if there is delay in one part of chain easily it will effect on the other part of chain as they work so close to each other.

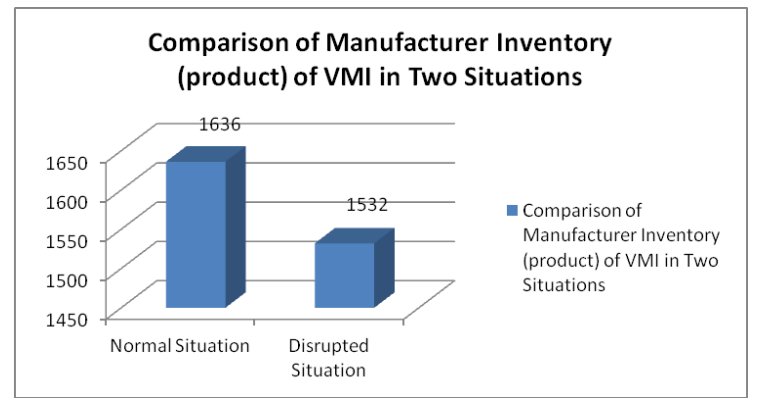

Fig. 5. Comparison of manufacturer inventory (product) of VMI in two situations

\section{Distributor Inventory Level}

Since the other member of supply chain is Distributor, In this part the focus will be on average inventory level of Distributor. According to simulation results the figure 6 is released. Fig. 6 indicates that when transportation disruption happens in VMI model, in contrast to the normal situation of system, the inventory level of distributor is decreased by $2.95 \%$. The result analyses are as follows;

VMI Model (Normal Situation): 
Average Distributor inventory: 542 units

VMI Model (Transportation Disrupted):

Average Distributor inventory: 526units

Reduction of Distributor inventory is: [(542 - 526) $\div 542]$

$\times 100=2.95 \%$

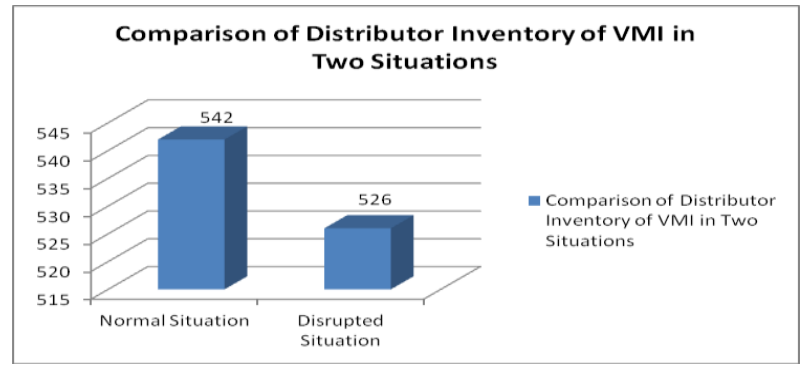

Fig. 6. Comparison of distributor inventory of VMI in two situations

\section{CONClusion}

It can be summarized that, transportation network is an integral part of supply chain. In addition, transportation disruption is an integral part of supply chain disruption, therefore, for having an efficient supply chain these issues must be considered deeply. Based on simulation results and also our analysis, it reveals that when the delays happen in the chain, there is a reduction in responded orders and system efficiency. Indeed the main important characteristics of VMI model are the information sharing and also close cooperation among the members of supply chain. According to this characteristic, the supply chain becomes more flexible and fast over-come towards unplanned disruption which may happen during its actions. Simulation results reveal that in VMI arrangement, although the system efficiency and average inventory level of members will reduce while the disruption happen in the system, the main characteristic of VMI which was information sharing and close cooperation between the partners lead to small percentages of reduction in both system efficiency and average inventory level. Moreover according to paper's examinations, the most critical and sensitive point to transportation disruption in
VMI structured supply chain is Manufacturer (product) warehouse by average inventory fluctuation of $6.35 \%$.

\section{REFERENCES}

[1] B. A. Chaouch, "Stock Levels and Delivery Rates in Vendor-Managed Inventory Programs," Production and Operations Management Journal, vol. 10, pp. 31-44, 2001.

[2] Centre for Research on the Epidemiology of Disasters, 2004 EM-DAT: The OFDA/ CRED International Disaster Database, Universite' Catholique de Louvain, Brussels.

[3] M. Christopher and H. Peck, "The Five Principle of Supply Chain Resilience," Logistics Europe Journal, vol. 12, pp. 16-21, 2004.

[4] A. N. Houshyar, M. Mukhtar, and R. S. Simulating, "The Effect of Supply Chain Risk and Disruption: A Malaysian Case Study," International symposium of information technology, vol. 1, no. 3, pp. 1362-1368, 2010.

[5] B. P. Gan, L. Liu, S. Jain, S. J Turner, W. Cai, and W. J. Hsu, "Distributed Supply Chain Simulation Across Enterprise Boundaries," in Proc. Winter Simulation Conference, vol. 2, pp. 1245-1251, 2000.

[6] Annual Review: Natural Catastrophes 2005, Munich Report, 2006. Munich Re Publications, Munich.

[7] L. Coleman, "Frequency of Man-Made Disasters in the 20th Century," Journal of Contingencies and Crisis Management, vol. 14, pp. 3-11, 2006.

[8] J. Husdal and S. Brathen, "Bad Locations Bad Logistics?" $12^{\text {th }}$ World Conference on Transport Reasearch, 2010

[9] Y. Sheffi, "Supply Chain Management Under the Threat of International Terrorism," The International Journal of Logistics Management, vol. 12, pp. 1-11, 2001.

[10] G. Sim, Dynamic Simulation and Supply Chain Management, Whitepapaer, 2007.

[11] D. P. Mitigating, "Supply Chain Disruption Risk Using Sense and Respond Framework," Ph.D. thesis, 2007

[12] Efficiency Machines. [Online]. Available: http://www. Ehow.com/how_8089003_efficiency_machines.html

Afsaneh Noori Houshyar is a Ph.D. student of Industrial Engineering in Department of Mechanical and Manufacturing System, Faculty of Engineering, University Putra Malaysia.

Mohammad Reza Tavakoli Baghdadabad is a DBA student in Graduate School of Business (GSB), Universiti Kebangsaan Malaysia

Azadeh Noori Hoshyar is a Ph.D. student of IT in Faculty of Engineering and IT, University Technology Sydney.

Riza Bin Sulaiman is a associate professor in Department of Industrial Computing, Faculty of Information Technology, Universiti Kebangsaan Malaysia 